\title{
Track 7. Advances on Sustainable Development in Higher Education
}

\author{
Nídia Caetano \\ School of Engineering / Polytechnic of Porto \\ LEPABE / Faculty of Engineering of University of Porto \\ Porto, Portugal \\ nsc@isep.ipp.pt
}

\author{
Manuel Felgueiras ${ }^{\dagger}$ \\ School of Engineering \\ Polytechnic of Porto \\ Porto, Portugal \\ mcf@isep.ipp.pt
}

\begin{abstract}
Sustainable development has been linked to the ecological, economic and social dimensions, and it appears from the outset that it is a complex task to include several very different aspects while planning and projecting. This multi-dimensional feature migrates to education sustainable development that is, as expected, a complex task. Traditional education based on specialization of subjects and unidirectionality of strategies has often proved to be insufficient. The present Track intends to be a space of debate of the challenges posed to Higher Education professionals as strategic partners for the development of different mindsets, able to tackle the real problems. ${ }^{1}$
\end{abstract}

\section{CCS CONCEPTS}

- Applied Computing $\rightarrow$ Physical Sciences and Engineering; - Applied Computing $\rightarrow$ Education; $\bullet$ Computers and Education $\rightarrow$ Computer and Information Science Education - curriculum, problem-based learning, self-assessment - Social and professional topics $\rightarrow$ Sustainability $\bullet$ Social and professional topics $\rightarrow$ Model curricula $\cdot$ Social and professional topics $\rightarrow$ Informal education $\bullet$ Social and professional topics $\rightarrow$ Student assessment.

\section{KEYWORDS}

Sustainable development, Higher education, Interdisciplinarity, Multidisciplinarity, TEEM, Transdisciplinarity.

\section{ACM Reference format:}

Nídia Caetano, Manuel Felgueiras. 2018. Track 7. Advances on Sustainable Development in Higher Education. In Proceedings of Technological Ecosystems for Enhancing Multiculturality conference, Salamanca, Spain, October 2018 (TEEM'18), 3 pages. https://doi.org/10.1145/123 4

Permission to make digital or hard copies of part or all of this work for personal or classroom use is granted without fee provided that copies are not made or distributed for profit or commercial advantage and that copies bear this notice and the full citation on the first page. Copyrights for third-party components of this work must be honored. For all other uses, contact the owner/author(s).

\section{Introduction}

The role of sustainability in higher education has been well recognized. Declarations on Sustainability in Higher Education (SHE) are pieces of international regulation.

Over the past 30 years research at universities has produced substantial data to advise about deterioration of the environment, resource scarcity and the need for sustainability. This put a deeper pressure on the universities, forcing them to reevaluate their role as a driver for sustainable development. However, it is well known that signing a declaration does not necessarily lead to implementation which is due to the lack of incentive structures. Presently, universities and intergovernmental institutions have developed more than 31 SHE declarations, and more than 1400 universities have signed a SHE declaration globally [1]. The number of declarations is still increasing, with a notable evolution of SHE definition. [2]. However, implementation inside universities is very slow.

Sustainability includes some degree of controversy and has a variety of meanings depending on the users, their backgrounds, interests and values, and the context in which it is used. In a postmodern world, pathways towards sustainable universities are unlikely to be developed without resistance, controversy, and even conflict. In fact, we live in a pluralistic society, characterized by multiple actors and diverging interests, values, perspectives, and constructions of reality [3].

As described, sustainable development is a vague, highly complex concept that is hard to understand. To teach this concept, current traditional structures and processes need to be broken. Different disciplines and subjects need to be integrated in university classes that need to be connected to real-world problems and actors. The

TEEM'18, October 2018, Salamanca, Spain (c) 2018 Copyright held by the owner/author(s). 123-4567-24-567/08/06 . . \$15.00 https://doi.org/10.1145/123_4 
typical didactic triangle (teacher, student and content) should no longer be designated by an active teacher who instructs passive students. This is considered a fundamental break with the general idea that knowledge is determined and provided by teachers and class instruction is then absorbed and reproduced by the students (i.e., traditional unidirectional educational processes). As an alternative, interaction between students and teachers needs to be re-organized in a way that directly generates a demand for learning in the sense of jointly searching for the meaning of the concept of sustainability both for the individual and for the systems in which they are also both embedded.

It should be noted that the new solutions will take place in complex systems and should cooperatively integrate the know-how of various disciplines thus is interdisciplinary.

The unique and traditional disciplinary approach in university education, applied to isolated systems represents an initial approach in the sense of having a treatable problem (i.e. with possible solution). However, it has the disadvantage of not allowing to apprehend and to understand the nature of the real problems, which are naturally multidisciplinary. It becomes necessary to understand that the essence of nature is inherently complex and interdependent. Education for sustainable development implies a paradigm shifting to a new approach that is able to contribute with new solutions to the new challenges in sustainable development [4,5]. While the principle of interdisciplinarity incentives for cooperation across different subjects and disciplines, transdisciplinarity concepts includes strong interaction between academics and practitioners in order to promote a mutual learning process between them. For instance, it is not possible to effectively research or teaching sustainable development of society without interacting with society. In addition, at this level we can perceive several levels of multidisciplinarity levels. Interdisciplinarity creates and promotes dialogue and exchanges between disciplines. It is no longer a fragmented vision but an enrichment from different disciplines. Transdisciplinarity works on objects that do not belong to one discipline. It aims to achieve a project through the use of different disciplinary activities. Pluridisciplinarity addresses an object of study according to the justaposition of multiple specialized looks. The problem lies in the fragmentation of approaches, although it is a way of approaching all aspects [6].

The sustainable development:

- Is intrinsically a multi-dimensional issue (economical, environmental, social);

- Is involved in a multitude of declarations and interpretations (dozen of declarations);

- Should be taught through multidisciplinary strategies (interdisciplinarity, transdisciplinarity, pluridisciplinarity)

As seen, sustainable development is a very complex task that calls for adequate strategies to be satisfactorily addressed.

\section{Works in this edition of Track 7}

This edition of TEEM'18, Track 7, has registered several works in many different domains, as summarized below.

The theme of Continuing Engineering Education and Sustainability was developed, and a declaration of commitment was presented as an outcome. It should be noted that statements are compromises between systems with completely independent legal rules. The persistence on new commitments are revealing and identifying the agents committed to the future. When these commitments are developed in a higher education environment, one must believe that we are sowing values that will impact the way future professionals act.

The remote experimentation approach was developed to seek to share resources, relating primarily to the social and economic dimension. Interestingly, there are recent approaches that use an environmental justification to this type of solution. The classes in the simulation environment are particularly interesting to the student because it allows to practice several possibilities of what if problems but presents the disadvantage of not showing Nature to act (no real feeling of the consequences). The laboratory classes fulfill this last object very well, nevertheless presenting some disadvantages, such as they require more time, they are more expensive, and they generate waste. Let us think about the amount of waste resulting from the chemistry classes of a school, university, state, country, etc. If we do the same exercise for several areas of knowledge study, we will easily find that the educational process generates a lot of waste. Remote Laboratories are a possibility for a more sustainable educational process, through sharing of experiments.

Blended Mobility as a way for the Sustainable Internationalization of Higher Education was developed above all in the social dimension. However, it also indirectly addresses the multiculturality [7], an important topic that is included in the conference designation.

The education of concepts for sustainability education oriented primary and secondary school are also presented in the form of MOOC. It is a development, especially in the social dimension, that curiously presents a profound change within the educational system itself, that starts to imitate the social model. In fact, in school teachers belong to a group of older people who lend their experience to a group of younger students. Typically, the education system operates in an open loop in the sense that, in the education system, students start in nursery school and end after higher education. Curiously some works shows closed-loop working, i.e., people (teachers and students) from more advanced teaching groups are developing means of support to teach students of the earlier stages of education, in a closed-loop way. This is an interesting example of a solution that aims to solve the complexity of education in sustainable development. 


\section{Conclusion}

This theme of education associated with sustainable development has been developed consistently in TEEM. Only a few of the reasons that justify the high requirement of this theme were presented. It is not surprising that only a few works by authors with special multidisciplinary abilities have been presented. There is still a long way to go, but Sustainable Development has an met History.

\section{ACKNOWLEDGMENTS}

Financial support of project POCI-01-0145-FEDER-006939 (Laboratory for Process Engineering, Environment, Biotechnology and Energy - LEPABE) funded by FEDER through COMPETE2020 - (POCI) Programa Operacional Competitividade e Internacionalização and by national funds through FCT \& Research Project UID/EQU/00305/2013.

\section{REFERENCES}

[1] T.S. Grindsted (2011). Sustainable universities - from declarations on sustainability in higher education to national law. Environmental Economics, 2(2), 2011.

[2] T. Wright (2004). The evolution of sustainability declarations in higher education. In: P.B. Corcoran \& A.E.J. Wals (Eds.), Higher Education and the Challenge of Sustainability: Problematics, Promise and Practice, 7-19. (c) 2004 Kluwer Academic Publishers. Netherlands.

[3] P.B. Corcoran, A.E.J. Wals (2004). The problematics of sustainability in higher education: a synthesis. In: P.B. Corcoran \& A.E.J. Wals (Eds.), Higher Education and the Challenge of Sustainability: Problematics, Promise and Practice, 87-88. (C) 2004 Kluwer Academic Publishers. Netherlands.

[4] G. Steiner, A. Posch (2006). Higher education for sustainability by means of transdisciplinary case studies: an innovative approach for solving complex, realworld problems. Journal of Cleaner Production, 14, 877-890. DOI=http://dx.doi.org/10.1016/j.jclepro.2005.11.054

[5] N. Caetano, D. López, J. Cabré (2015). Learning sustainability and social compromise skills: a new track is born. In: Proceedings of the 3rd International Conference on Technological Ecosystems for Enhancing Multiculturality (TEEM '15). ACM, New York, NY, USA, 525-528. DOI=http://dx.doi.org/10.1145/2808580.2808660

[6] F. Fourati-Jamoussi, M.J.F. Dubois, M. Agnès, V. Leroux, L. Sauvée (2018). Sustainable development as a driver for educational innovation in engineering school: the case of UniLaSalle. European Journal of Engineering Education 4, 1 19.

[7] N. Caetano, J. Rocha, J.C. Quadrado, J.M. Cardoso, M.C. Felgueiras (2015). Teaching sustainability in a multicultural environment. In : Proceedings of the 3rd International Conference on Technological Ecosystems for Enhancing Multiculturality (TEEM '15). ACM, New York, NY, USA, 145-150. DOI=http://dx.doi.org/10.1145/2808580.2808603 